TAP CHÍ KHOA HỌC ĐẠI HỌC TÂN TRÀO
ISSN: $2354-1431$

\title{
NGHI LẼ̃ SLIÊN CỦA NGƯờI NÙNG Ở THÁI NGUYÊN
}

\author{
Đàm Thị Tấm ${ }^{1 *}$, Hoàng Thị Phương Nga ${ }^{l}$ \\ ${ }^{1}$ Khoa Du lịch - Truò̀ng Đại học Khoa học - Đại học Thái Nguyên \\ *Email: tamdt@tnus.edu.vn
}

\section{Thông tin bài viết}

Ngày nhận bài:

28/7/2020

Ngày duyệt đăng:

20/9/2020

Từ khóa:

Sliên, Nùng, văn hoá, diễn xuớng dân gian, tâm linh,

Thái Nguyên.

\begin{abstract}
Tóm tắt
Sliên của người Nùng Thái Nguyên là một loại hình nghệ thuật diễn xướng dân gian tổng hợp mang đậm chất Shaman giáo và được coi như một liệu pháp chữa bệnh tinh thần trong đời sống của cộng đồng. Từ xa xưa, mỗi khi trong cuộc sống gặp hiện tượng lạ không thể lý giải được, họ thường tổ chức Sliên để cầu cúng, cầu mong cho gia đình được bình yên, may mắn, khỏe mạnh, làm ăn thuận lợi. Qua việc tiếp cận, thống kê, khảo sát và phân tích các giá trị của Sliên, chúng tôi nhận thấy nghệ thuật diễn xướng dân gian này không chỉ là thể loại ca nhạc tín ngưỡng lâu đời thể hiện đời sống tâm linh phong phú của người Nùng mà còn là hình thức sinh hoạt văn hoá văn nghệ độc đáo. Nó không chỉ là phương tiện cầu cúng để chữa bệnh mà đã trở thành loại hình nghệ thuật diễn xướng dân gian kể chuyện tín ngưỡng bằng các yếu tố văn hoá nghệ thuật.
\end{abstract}

\section{Giới thiệu về người Nùng ở tỉnh Thái Nguyên}

Trong Kiến văn tiểu lục của Lê Quý Đôn có ghi: “Giống người Nùng đều là người 12 thổ châu ở Tiểu Trấn Yên, Quy Thuận, Long Châu, Điền Châu, Phủ Châu, Thái Bình, Lôi Tủ Thành và Huóng Vũ thuộc Trung Quốc làm nghề cày cấy, trồng trọt, cùng chịu thuế khóa lao dịch, mặc áo vằn vải xanh, cắt tóc, trắng răng, có nguời trú ngụ đã đến vài ba đời, đổi theo tập tục ngườ Nam, quan bản thổ thương cấp cho ho một số ruộng làm nguời phần, bắt ho chịu binh xuất. Các xú Lang Sơn, Cao Bằng và Thái Nguyên đều có giống người này” [1].

Người Nùng ở Việt Nam phần lớn từ Quảng Tây (Trung Quốc) di cư sang Việt Nam cách đây khoảng 200 - 300 năm bởi lý do thiên tai, địch họa... Vùng đất đầu tiên mà họ dừng chân để sinh sống chính là các tỉnh biên giới phía Bắc Việt Nam như: Cao Bằng, Lạng Sơn. Sau đó, người Nùng tiếp tục đi xuống vùng núi thấp như Thái Nguyên vào khoảng cuối thế kỉ XVIII đầu thế kỉ XIX [2].
Thái Nguyên là vùng đất có khá đông người Nùng cư trú với 63.816 người chiếm $5,7 \%$ dân số toàn tỉnh. Hiện nay trên địa bàn tỉnh có 5 nhóm địa phương của dân tộc Nùng: Nùng Phàn Slình, Nùng Cháo, Nùng Inh, Nùng An và Nùng Giang. Nhóm Nùng Cháo cư trú lâu đời nhất, tiếng nói của họ gần giống như người Tày, cư trú ở huyện Đồng Hỷ, Võ Nhai, Đại Từ. Nhóm Nùng Phàn Slình, có nguồn gốc di cư từ Bình Gia, Văn Quan, Cao Lộc (Lạng Sơn) cư trú ở Võ Nhai, Đồng Hỷ, Đại Từ. Nhóm Nùng An, Nùng Inh, Nùng Giang có nguồn gốc từ Cao Bằng hiện cư trú ở huyện Phú Lương, Võ Nhai, Phú Bình [3].

Phần lớn người Nùng Thái Nguyên đều ở nhà sàn bốn mái, lợp ngói (người Nùng Phàn Slình ở Đồng Hỷ, Võ Nhai), nhà đất và nhà xây (người Nùng Cháo, Nùng An, Nùng Inh và Nùng Giang ở Đồng Hỷ, Phú Bình, Phú Lương). Họ cư trú quây quần với nhau thành từng bản nhỏ dựa vào lưng chừng đồi, ở giữa là cánh đồng, tạo thành từng không gian khép kín riêng, không xen kẽ với các dân tộc khác. 
Qua tìm hiểu thực tế hiện nay cho thấy, người Nùng ở Việt Nam có hơn chục nhóm địa phương khác nhau nhưng chỉ có 3 nhóm làm Sliên, đó là: nhóm Nùng Cháo, nhóm Nùng Inh và nhóm Nùng Phàn Slình. Còn lại các nhóm khác hầu như không có hoạt động văn hoá tâm linh này. Tại Thái Nguyên, chỉ có nhóm Nùng Phàn Slình còn thực hành hoạt động nghi lễ này ở các huyện: Đồng Hỷ, Võ Nhai (Nùng Phàn Slình Slửa Lì), Phú Bình (Nùng Phàn Slình Cúm Cọt).

Qua khảo sát, hiện nay hình thức diễn xướng dân gian Sliên chủ yếu diễn ra trong cộng đồng người Nùng ở các xã Hoá Trung, Quang Sơn, Tân Long, Văn Hán (huyện Đồng Hỷ), xã Nam Hoà (huyện Phú Bình) của tỉnh Thái Nguyên. Các gia đình người Nùng ở những địa bàn này vẫn cần đến Sliên như một liệu pháp chữa bệnh tinh thần cho những người già chủ yếu trên 60 tuổi. Đối với giới trẻ, do ảnh hưởng bởi những tư tưởng và trào lưu mới, họ không hứng thú với loại hình nghệ thuật độc đáo này của dân tộc. Xét ở góc độ tâm lý tộc người, không chỉ thế hệ già mà thế hệ trẻ họ vẫn muốn giữ gìn bản sắc văn hoá của dân tộc mình cho thế hệ sau. Tuy nhiên, họ vẫn loay hoay và không biết bằng cách nào để giữ gìn và phát huy được những yếu tố văn hoá riêng, độc đáo của dân tộc mình có sức sống với thời gian. Vì thế, việc tìm hiểu về hình thức nghệ thuật diễn xướng Sliên này hy vọng cũng góp phần vào việc lưu giữ và truyền lại cho các thế hệ trẻ được biết đến.

\section{Vũ trụ quan của người Nùng thể hiện trong} Sliên

Người Nùng cho rằng, thế giới tâm linh được chia làm ba tầng tương ứng với ba mường: Mường Trời, Mường Đất và Mường Nước [4]. Trong đó, Mường Trời là nơi cư ngụ của các vị thần linh tối cao quyết định sự sinh tồn và số phận của mọi con người. Trên Trời có: Ngọc Hoàng, Phật Bà Quan Âm, vua Hành Khiển, Nam Tào Bắc Đẩu, Mẻ Bjoóc (Mẹ Hoa) - Bà Mụ phân phát con người cho thế gian. Bề dưới còn có các vị tướng lĩnh và binh lính dưới quyền Ngọc Hoàng. Thần dân của Mường Trời là linh hồn của những người chết cư trú theo dòng họ gia đình thành từng phường riêng, như sau: phường slao báo (phường thanh niên nam nữ), phường phi chài (phường trẻ con), phường phi sluơng (phường ma chết bất đắc kì tử)... Ngoài ra còn có các tầng lớp phu phen, tạp dịch; các loại quỷ thần.

Mường Đất là nơi sinh sống của con người, được chia thành các tầng. Mỗi tầng lại có những dạng thần linh, ma quỷ khác nhau trú ngụ. Cũng theo quan niệm của họ, thuở ban đầu, đất và trời rất gần nhau. Con người có thể leo lên trời, chỉ cần bắc cầu thang đi chợ trời, hay rủ trai gái hát sli trong các dịp lễ tết.

Mường Nước là mường của Long Vương Địa Phủ, cũng là nơi Long Vương giam giữ linh hồn người chết. Sau khi chết, hồn bị đẩy xuống địa ngục để được xem xét tội lỗi nặng nhẹ, và chịu cực hình. Từ đây, linh hồn có thể đầu thai vào kiếp sau làm một con người khác hoặc con vật khác (điều này do ảnh hưởng bởi màu sắc của yếu tố Phật giáo). Để đi được đến nơi ở của Long Vương phải đi qua 12 cửa nước, mỗi cửa đều có một vị thần cai quản. Cuối cửa 12 cửa địa ngục là cung điện của Long Vương.

Bên cạnh vũ trụ quan 3 mường, trong Sliên cũng thể hiện quan điểm về khái niệm "ma" (phi). Phi đồng nghĩa với linh hồn hay quan niệm vạn vật hữu linh và được chia làm hai loại: ma lành và ma dữ. Họ quan niệm ma hay thần đều tồn tại ở cả ba mường: Trời, Đất, Nước (Địa phủ/Âm phủ). Ma trên trời là các Then, Pụt, tiên thần và tổ tiên (trổ) được lập đền miếu để thờ cúng, nơi mà các $p h i$ thần này được mời từ trời về hưởng lễ chứng giám sự thỉnh cầu của người trần. Các loại phi ở trên mặt đất như phi ở núi sông (thuồng luồng), rừng, ruộng, rẫy... thường trú ngụ ở các đỉnh núi, vùng núi lớn, cây to... nói chung không hại ai, nhưng nếu vô tình hễ xúc phạm đến thì phải làm lễ tạ lỗi. Phi dưới đất thì chuyên gây ra ốm đau cho mọi người, nên phải nhờ các thầy mo, thầy tào vào vùng đó để trừ ma giải bệnh.

Người Nùng cho rằng con người hoàn toàn khoẻ mạnh thì hồn vía (khoăn) luôn ngụ đầy đủ trong một cơ thể, nam thì có 7 , nữ thì có 9 . Vía là một cái bóng vô hình tồn tại trong các bộ phận cơ thể con người quyết định tính cách và hình thể của con người [5]. Vía có thể rời khỏi xác đi lang thang, có khi còn lên được cả mường Trời theo sự dẫn dắt của các thầy cúng. Nếu vì một lý do nào đó, một vía bị bắt đi thì người sẽ ốm đau bệnh tật không thể chữa khỏi được, để lâu sẽ chết hoặc sẽ ảnh hưởng đến gia đình, dòng họ và cộng đồng. Người bị đau ốm ở bộ phận nào thì có nghĩa là do vía của bộ phận đó bỏ xác chạy ra ngoài. Nếu vía không còn ở trong cơ thể nữa, tức là con người sẽ chết. Trong khi con người ta chết đi, không còn thể xác cho vía trú ngụ nữa thì vía sẽ chuyển từ khoăn sang phi, tức là chuyển từ vía sang ma. 


\section{Quan niệm của người Nùng về những người hành nghề Sliên}

Trong đời sống người Nùng ở Việt Nam nói chung, nếu con người gặp nhiều khó khăn, rủi ro, bệnh tật họ thường thông qua các nghi lễ cúng bái cầu mong thần linh phù hộ hay giải thoát cho mình. Những người có thể thực hành các nghi lễ trong cộng đồng đó là các bà Pựt, ông Pựt. Những người đó khi hành nghề Sliên là nữ được gọi là giàng, nam giới là then giàng [5].

Người làm Sliên chủ yếu được truyền theo truyền thống gia đình, dòng họ. Thực tế cho thấy, chính người con gái được bên ngoại truyền nghề cho nhưng chỉ sau khi đã lấy chồng mới được hành nghề. Một gia đình ngành Sliên sẽ có đủ thầy cha (thầy Tào), thầy mẹ (Pựt) và cũng có các thứ bậc anh chị em, bác bá... Vì vậy điểm giống với thờ cúng tổ tiên là họ cũng phải thờ các thầy cha, thầy mẹ của mình khi các vị này quá cố gọi là thờ tổ sư. Tuy nhiên điểm khác với việc thờ cúng tổ tiên trong gia đình là người làm Sliên có thể có từ một tới nhiều thầy cha, thầy mẹ trong trường hợp họ muốn tăng sắc mà chẳng may thầy cha, thầy mẹ của họ đã qua đời, buộc họ phải mời người khác thay thế.

Thờ cúng tổ sư là đối tượng chủ yếu và quan trọng nhất, trở thành nguyên tắc hành nghề của Sliên. Trong thực tế, trong quan niệm của các thầy cúng người Nùng thì tổ sư bao gồm những vị tiền bối có hành nghề cúng bái của gia đình qua các thế hệ và các vị thầy cha, thầy mẹ trực tiếp làm lễ cấp sắc, tăng sắc cho họ. Nói cách khác thờ tổ sư trong Sliên cũng là một hình thức thờ cúng tổ tiên. Điều này thể hiện rõ ở hầu hết mọi dòng Sliên ở chỗ mỗi người làm nghề Sliên đều phải nhớ đủ danh sách tổ tiên làm nghề của gia đình mình và thầy cha, thầy mẹ của mình để thờ phụng tại nhà cũng như khi đi hành lễ.

Theo người Nùng, các Sliên hành lễ để chữa bệnh, cầu yên, nối số, giải hạn, làm lễ chuộc hồn, đưa hồn lên cõi thần tiên, kể cả lễ 49 ngày của người đã chết... để giúp người dân được khoẻ mạnh, không bệnh tật, yên tâm làm ăn. Vì thế, các đối tượng này được cộng đồng rất tôn sùng và coi trọng. Hầu như bản nào cuả người Nùng cũng đều có các thầy hành nghề tôn giáo tín ngưỡng: Mo, Tào và Pụt. Tuy nhiên, tuỳ từng địa bàn lại có những vị hành nghề Sliên có vùng lại không.

\section{Những nghi lễ điển hình trong Sliên \\ 4.1. Nhũng nghi lễ Sliên trong năm}

Trong một năm tính từ đầu năm trở đi, những người hành nghề Sliên đều tổ chức các nghi lễ cho bản thân, gia đình và cộng đồng để cầu sức khoẻ và bình an cho con người và vạn vật. Sau đây là những nghi lễ cơ bản của Sliên vẫn còn tồn tại trong cộng đồng người Nùng ở Thái Nguyên.

Lễ giải hạn: Nghi lễ này thường được tổ chức vào tháng Giêng đầu xuân năm mới với mục đích giải đi các loại sao xấu (Vân Hán, Kế Đô), các loại hạn (Bạch Hổ, Diêm La, Thiên La...) ảnh hưởng đến đời sống của con người. Lễ vật bao gồm: 01 lễ tam sinh (01 thủ lợn, 01 gà, 01 vịt), vàng mã, hoa quả các loại... Phần lớn các gia đình người Nùng hiện nay đều tổ chức nghi lễ này. Họ rất coi trọng các vị Sliên và luôn đón các thầy đến nhà làm lễ vào dịp năm mới.

Lễ giải hạn bất thường: khi gia đình có người mất vì tai nạn, hoặc có hiện tượng lạ như chim sa cá lặn, cầy cáo chạy qua nhà, rắn rết bò vào nhà... (theo quan niệm dân gian của người Nùng những con vật này luôn mang lại điềm xấu cho gia chủ nên buộc phải làm Sliên để hoá giải). Nếu như không làm, họ sẽ không yên tâm về mặt tinh thần.

Lễ cầu kiều (cầu tự): Người Nùng quan niệm, do vợ chồng phạm vào cung cô thần quả tú và có lỗi với Bà Mụ nên không có con. Vì thế, họ phải làm nghi lễ bắc cầu để xin Bà ban hoa. Nếu đứa trẻ sinh ra là con trai thì bông hoa để trên Bàn Mụ là màu xanh, con gái là màu hồng. Trường hợp nếu trẻ sơ sinh không nuôi được mà chết yểu thì gia đình phải làm lễ trả hoa cũ cho Bà Mụ và xin hoa mới (quét bjoóc héo).

Nghi lễ khác: đầy tháng (khai bươn), vào nhà mới (khẩu rườn mấu), đám cưới (slỉnh lẩu), mừng sinh nhật (hết khoăn)... Mục đích của những lễ này là báo cáo lên các bậc tổ tiên về chứng giám và ban phước ban lộc cho con cháu được khoẻ mạnh, ăn nên làm ra... Lễ vật dâng lên thường là từ $5-7$ con gà, 01 thủ lợn, 01 con vịt, hoa quả, bánh kẹo kèm theo.

Lễ Sliên chuộc hồn (tháy phi): nghi lễ này chỉ được thực hiện trong đám ma, đám 49 ngày, cắt tang (thốt háo). Mục đích của nghi lễ để chuộc vong hồn người chết ra khỏi ngục. Vì theo quan niệm của người Nùng, khi người chết đi, vong hồn sẽ bị đày xuống địa ngục để chịu tội và học tập các lời răn dạy của các quan dưới âm phủ, hết 49 ngày gia đình phải mời thầy về chuộc. Nếu không hồn ma sẽ trở nên 
lang thang, không nơi nương tựa, trở thành ma đói ma khát (phi slương).

Sliên chũa bệnh (chấu khẩy): Người ốm không rõ nguyên nhân, có thể do qua những khu vực linh thiêng như: đền, miếu, ngã ba, ngã tư, cây đa, cây đề... bị ma bắt mất hồn, không được tỉnh táo và khoẻ mạnh. Nếu bệnh nặng gia chủ phải mời thầy Sliên đến làm lễ giải. Lễ vật gồm: 01 con gà, tiền vàng, hoa quả và bánh kẹo. Trong trường hợp bệnh nhẹ, gia chủ chỉ cần mang hương, tiền, gạo đến nhà thầy Sliên để bói và gọi hồn quay trở về nhập lại vào thân xác.

Các lễ vật trong Sliên đều ít nhiều được biến hóa theo trí tưởng tượng phong phú của họ: Quả bí xanh là con lợn, hoa chuối rừng là con gà trống; chiếc thuyền bẹ chuối là tượng trưng cho đoàn thuyền loan thuyền phượng; tảng bột nặn - thậm chí là một chiếc bánh chưng bọc giấy màu là quả núi Su-mi, là quả núi thiêng của thần Phật ngự ở trên trời cao. Thậm chí, binh mã - một lực lượng khá điển hình lại được tượng trưng qua gạo trắng (như hiện tượng chia gạo tượng trưng cho việc phân binh mã trong lễ cấp sắc).

Hàng năm, vào đêm giao thừa là thời điểm thầy Sliên thực hiện nghi lễ khai ấn đầu xuân. Kể từ giờ phút này, thầy bắt đầu được thực hiên nghi lễ tại các gia đình. Nếu gia chủ nào muốn "mở hàng" cho thầy buộc phải mang một đôi gà đến xin làm lễ. Dịp 15/3 âm lịch là thời điểm Giỗ Tổ Sliên thường được tổ chức rất to, rất linh đình.

Tháng 4 người Nùng không tổ chức cúng bái vì cho rằng đây là tháng có nhiều bệnh tật, vận hạn, nhiều quan dịch, nước sông Ngân Hà lên cao nên không nên làm lễ. Vào dịp Tết Đoan ngọ mùng 5 tháng 5 , Sliên tổ chức nghi lễ đón tướng nhà Trời xuống phát bùa may mắn để tiêu trừ bệnh tật. Tết Slíp slí 14/7 âm lịch, Sliên tổ chức nghi lễ dâng hoa dâng quả (lẩu mạy lẩu mác). Vào dịp tết Trung thu 15/8 âm lịch tổ chức lễ đón Nàng Hai (tẳng Nàng Hai). Ngày 10/10 âm lịch, Sliên tổ chức lễ dâng cốm đón tổ sư (Lẩu khẩu mẩu). Vào tháng 12 âm lịch, họ thường làm lễ phong ấn trước ngày 20 (tuỳ từng thầy, tuỳ từng dòng họ, thời điểm). Khi làm lễ xong, họ dán giấy đỏ vào đàn tính, buông rèm bàn thờ xuống, đổ gạo lên nhạc xoóc và ấn rồi để trong chậu đồng. Kết thúc một năm làm lễ cho người dân của thầy Sliên.

\subsection{Những nghi lễ nhỏ liên quan đến thầy Sliên}

Sliên của người Nùng chịu sự tác động của Tam giáo mà chủ yếu là Đạo giáo thông qua giáo lý của thầy cúng có gốc gác từ vùng phía nam của Trung Quốc. Điều này thể hiện rõ nhất qua lễ cấp sắc của
Sliên có sự tham gia chủ đạo của thày Tào, người được coi là thầy cha của đệ tử, thay mặt Ngọc Hoàng Thượng Đế đứng ra cấp sắc cho đệ tử. Với mỗi thầy Sliên từ khi được cấp sắc chứng nhận hành nghề cho đến khi chết, họ phải trải qua những nghi lễ sau:

Lễ cấp sắc: Nếu như trước đây, các thầy Sliên Nùng không trải qua nghi lễ cấp sắc thì hiện nay đã có sự giao thoa văn hoá với Then Tày nên những người làm Sliên Nùng đều trải qua nghi lễ này.

Lễ tăng sắc: Khi thầy Sliên nhận thấy đã đủ trình độ hành nghề và điều kiện kinh tế, họ sẽ tổ chức lễ này. Mục đích của lễ là tăng thêm cấp bậc cao hơn. Trong nghi lễ này có tiết mục đón Tướng (tẳng Tuớng). Tướng Cả: đây là vị tướng có quyền năng cao nhất, có trách nhiệm phân chia lễ cho con người; Tướng Ké (vị Tướng Già): là ông Tổ to nhất trong số các ông tổ; Tổ sư: có khoảng $4-5$ vị về nhập vào Sliên. Đây có thể là các bà cô trẻ; Tướng Khách: Khách Vàng (Hoàng) đó là: Phiêng cai quản phía Nam, các vị tiên trên trời thấy nghi lễ Sliên diễn ra vui, cùng nhau bay lượn đợi thụ lễ và ban lộc cho con người. Mọi người đến dự lễ cũng chuẩn bị quà: tràng hoa, đôi giày, áo, kẹo, tiền... để làm quà cho các vị thần tiên này. Sau đó, các vị thần tiên lại ban lại quà để mọi người dự lễ mang về phát lộc lại cho con cháu trong gia đình; Tướng Hổ Lang: là ông Hổ trên rừng, được coi như Tứ phủ về trấn đàn tràng. Lễ vật dâng cho ông phải có đầu lợn, răng ông cắn vào đầu lợn rồi ném về phía bàn thờ. Ông Hổ ngồi trên cây gai (co nam) rồi nhẫm trên than hồng. Đó là biểu hiện của ngựa hồng (ma hồng) thể hiện sự oai phong lẫm liệt, giương oai với người trần thế.

Lễ cáo lão: Khi các thầy Sliên đã già yếu, không đủ sức khoẻ để hành nghề, họ sẽ tổ chức lễ cáo lão để không làm nữa. Nhưng họ không được bỏ bàn thờ Sliên, cũng như nghề Sliên của dòng họ. Người Nùng có quan niệm, khi sống ở thế giới trần gian làm Sliên thì khi chết trở thành quan âm và vẫn tiếp tục hành nghề. Thực tế cho thấy, đại đa số các dòng Sliên không cho cáo lão mà phải làm cho đến cuối đời. Khi mất đi các thầy Sliên mới được thăng chức lần cuối để khi về thế giới bên kia họ vẫn tiếp tục hành nghề (có những dòng Sliên quy định 9 dây, 13 dây và 15 dây). Đối với các dòng Sliên của người Nùng, các trò không được phép hơn thầy về số lượng dây trên mũ.

\section{Bảo tồn và phát huy giá trị của Sliên}

Với mục tiêu lấy văn hóa làm nền tảng tinh thần của xã hội, là động lực thúc đẩy phát triển kinh tế xã hội, tỉnh Thái Nguyên đang tích cực gìn giữ và bảo tồn những nét văn hóa dân gian của dân tộc Nùng nói riêng và các dân tộc khác trên địa bàn tỉnh 
nói chung. Phát huy nét đẹp văn hóa đặc biệt là văn hoá các dân tộc thiểu số đang được lưu truyền và phục hồi những bản sắc đã bị mai một, là trách nhiệm của mỗi cá nhân và cộng đồng các dân tộc trên địa bàn huyện.

Tựu chung lại, Sliên của người Nùng ở Thái Nguyên là một loại hình nghệ thuật diễn xướng dân gian tổng hợp mang đậm chất shaman giáo hiện nay vẫn đang được cộng đồng dân cư truyền thừa và thực hành. Thông qua các nghi lễ trong Sliên, người Nùng Thái Nguyên đã thể hiện những ý niệm và niềm tin về nhân sinh quan và vũ trụ quan của mình rất phong phú và đặc sắc.

Hiện nay, các gia đình người Nùng truyền thống (có ông bà, cha mẹ ở cùng con cái) vẫn sử dụng Sliên như một liệu pháp tinh thần nhằm mang lại sự an tâm cho người già, người bị bệnh không rõ nguyên nhân và cầu bình an cho năm mới. Điều đó minh chứng một điều, liệu pháp chữ bệnh tinh thần của Sliên là thực sự có ý nhĩa và có tác dụng một phần nào đó trong đời sống của người Nùng. Bóc tách đi những yếu tố ma mị, huyền bí, hình thức diễn xướng Sliên hàm chứa ảnh xạ về những tín ngưỡng nguyên thủy và lịch sử tộc người Nùng. Chính vì thế, việc bảo tồn và việc khai thác các giá trị của Sliên đối với phát triển văn hóa - xã hội hiện nay là một điều cần thiết nhằm giới thiệu, quảng bá nét văn hóa độc đáo này trong dòng chảy của cuộc sống đương đại.

\section{REFERENCES}

1. Le Quy Don (translation - 1977), "The text of sub-continent" - Complete Le Quy Don, Volume 2, Social Science Publishing House

2. Hoang Nam (1992), The Nung ethnic group in Vietnam, National Cultural Publishing House.

3. Provincial Party Committee - People's Council

- Thai Nguyen Provincial People's Committee (2009), Thai Nguyen Land, National Political Publishing House.

4. Institute of Ethnology (1992), Tay and Nung ethnic groups in Vietnam, Hanoi

5. Nguyen Thi Yen (2009), Tay folk beliefs, Nung, Social Science Publishing House

\section{NUNG'S SLIEN IN THAI NGUYEN PROVINCE}

\begin{tabular}{l}
\hline Article info \\
\hline Recieved: \\
28/7/2020 \\
Accepted: \\
20/9/2020 \\
\hline
\end{tabular}

Keywords: Slien, Nung, Culture, folk proponent, spirituality, Thai Nguyen.

\begin{abstract}
The Nung's Slien is a type of synthetic folk art in Thai Nguyen, it is a Shamanisme and is regarded as a spiritual cure in the life of the community. Long time ago, whenever in life, they encounter a strange phenomenon and cannot be explained, the Nung people often organize the Slien to pray for the family to be peaceful, lucky, healthy, business advantage. By reaching, statistical, surveying and analyzing the values of the Slien, we recognize that this folk art is not only a genre of long - time music that is rich in spiritual life, but also a form of unique cultural activities. It is not only the means of prayer for healing that has become the kind of artistic vocal folk narrative of beliefs by artistic cultural elements.
\end{abstract}

